\title{
Morphological and Biochemical Studies of the Yellow and Purple-red Petal Pigmentation in Paeonia delavayi
}

\author{
Qianqian Shi ${ }^{1}$ \\ College of Landscape Architecture and Arts, Northwest A\&F University, \\ Yangling 712100, Shaanxi, China; National Engineering Research Center \\ for Oil Peony, Yangling 712100, Shaanxi, China; State Key Laboratory of \\ Tree Genetics and Breeding, Beijing 100091, China; and Key Laboratory of \\ Tree Breeding and Cultivation of State Forestry Administration, Research \\ Institute of Forestry, Chinese Academy of Forestry, Beijing 100091, China
}

\section{Long $\mathbf{L i}^{1}$}

National Engineering Research Center for Oil Peony, Yangling 712100, Shaanxi, China; and College of Forestry, Northwest A\&F University, Yangling 712100, Shaanxi, China

\section{Lin Zhou and Yan Wang ${ }^{2}$}

State Key Laboratory of Tree Genetics and Breeding, Beijing 100091, China; and Key Laboratory of Tree Breeding and Cultivation of State Forestry Administration, Research Institute of Forestry, Chinese Academy of Forestry, Beijing 100091, China

Additional index words. Paeonia delavayi, vacuolar $\mathrm{pH}$, metal ion, pigments, gene expression analysis

\begin{abstract}
Paeonia delavayi is a species endemic to Southwest China and an important genetic resource for flower color breeding of tree peonies. The mechanisms underlying the flower coloration of this plant have not been fully elucidated. In this article, the petals of yellow-colored individual (PI) and purple-red-colored individual ( $\mathrm{Pd})$ of $P$. delavayi were studied. And anatomical observations revealed that a large amount of yellow protoplasts and a small amount of colorless protoplasts were located in the yellowcolored PI petals, whereas a mixture of purple, red, and pink protoplasts were observed in the purple-red-colored Pd petals. The PI cells were subrotund and flat, whereas the Pd cells were irregularly polygon-shaped and bulging. Chemical analyses were performed, and the results indicated that significant differences occurred between the cell sap $\mathrm{pH}$ of the PI and Pd flowers and large differences occurred in the contents of Fe and $\mathrm{Al}$ between $P I$ and Pd. Cyanidin- and peonidin-based anthocyanins with flavones and flavonols as copigments determined the $\mathrm{Pd}$ flower color, whereas chalcone 2 ' $\mathrm{G}$ with apigenin 7- $\mathrm{O}$ neohesperidoside and chrysoeriol 7-O-glucoside as copigments determined the yellow color of PI. Correspondingly, the genes dihydroflavonol 4-reductase (DFR) and anthocyanidin synthase $(A N S)$ were significantly highly expressed in $\mathrm{Pd}$, whereas chalcone isomerase $(C H I)$, flavanone 3-hydroxylase $(F 3 H)$, flavone synthase $(F N S)$, flavonol synthase $(F L S)$, flavonoid 7-O-glycosyltransferase $(7 G T)$, and 2' 4' 6' 4-tetrahydroxychalcone 2 -glucosyltransferase $(T H C)$ had high transcript levels in $P I$ relative to $P d$. The results indicate that the color variation of $P$. delavayi petals may be related to a delicately controlled balance of the aforementioned factors.
\end{abstract}

Paeonia delavayi is an unique wild tree peony species with variously colored individuals including yellow, orange, red, dark red, and purple-red occurring both within and between populations, and the yellow colored individuals are considered the most precious resource for cultivar breeding (Hong and Pan, 1999, 2005a, 2005b, 2007; Hong et al., 1998; Li et al., 2011). Moreover, the

Received for publication 2 Apr. 2018. Accepted for publication 30 May 2018.

${ }^{1}$ These authors contributed equally to this work.

${ }^{2}$ Corresponding author. E-mail: wyancaf@163.co. antioxidant activity of the yellow-colored flowers of $P$. delavayi is higher than that of other yellow flowers, and this activity indicates its potential for use in drug development or functional food development ( $\mathrm{Li}$ et al., 2009).

In certain species, flavonoids, particularly anthocyanidins, are the primary contributors to the different coloration of flowers (Tanaka and Ohmiya, 2008; Suzuki et al., 2016). To date, more than 30 different flavonoids, including anthocyanins and multiform glycosides of flavones and flavonols, have been identified and quantified from different groups and several wild species of tree peony
(Hosoki et al., 1991; Wang et al., 2001a, 2001b, 2005; Zhang et al., 2007). Wang et al. (2001a) analyzed the composition and content of flower pigments of seven wild tree peonies and found that pelargonidin $(\mathrm{Pg})$ based anthocyanins were not detected in any accessions in the subsection Delavayanae and that the purple flowers of $P$. delavayi primarily contained peonidin-3, 5-glucosides (Pn3G5G). Zhou et al. (2011) investigated the pigment composition of the yellow petals of $P$. delavayi wild population in Yunnan Province, China, and found that the primary components were chalcone, flavone, and flavonol, including isosalipurposide, kaempferol $(\mathrm{Km})$, quercetin $(\mathrm{Qu})$, isorhamnetin (Is), chrysoeriol (Ch), and apigenin (Ap) glycopyranoside. In addition, reports have indicated that the petal epidermis cell shape can affect flower color. Conical cells lead to darker flower colors and improved color saturation. On the contrast, flat cells lead to lighter flower colors. For example, the magenta flower color of Antirrhinum majus changes to pink when conical epidermal cells are flattened (Noda et al., 1994). The length and arrangement of Iris tectorum petal epidermal cells also have certain influence on the flower color (Yoshida et al., 1995), and epidermal cells with protruding papillae can generate a velvet sheen on the petals as in Anagallis monelli L. (Quintana et al., 2007). In tree peony, the epidermal cells of Paeonia rockii and Paeonia ostii were all elongated and explanate (Shi et al., 2017). Flower coloration is also linked to metal ions and vacuolar $\mathrm{pH}$ differences, such as in Tulipa gesneriana (Momonoi et al., 2009; Shoji et al., 2007, 2010), Hydrangea macrophylla (Ito et al., 2009; Schreiber et al., 2010, 2011), and Ipomoea tricolor (Yoshida et al., 2005, 2009a, 2009b). Thus, we can infer that the variously colored flowers of $P$. delavayi are the result of certain physiological differences. However, the precise mechanisms involved remain uncertain, and comprehensive studies of color formation in $P$. delavayi or other tree peony flowers have not yet been reported.

In the present work, the major factors underlying the formation of various colorations of $P$. delavayi were investigated in individuals with purple-red (Pd) and yellow flowers ( $\mathrm{Pl}$ ) from a wild population in Yunnan Province, China, and the anatomy of morphology of petals, protoplast features, and pigment compositions were analyzed. Cell sap $\mathrm{pH}$ and metal ion contents of the petals were also investigated. To the best of our knowledge, this work is the first comprehensive exploration of the formation of flower color in $P$. delavayi, and the analysis may provide additional insights into the mechanism of color formation in tree peonies.

\section{Materials and Methods}

Plant material. The yellow-colored individuals $(\mathrm{Pl})$ and purple-red individual $(\mathrm{Pd})$ of $P$. delavayi were introduced from 
a wild population in Shangri-La County (lat. $27^{\circ} 57^{\prime} \mathrm{N}$, long. $99^{\circ} 35^{\prime} \mathrm{E}$ ), Yunnan Province, China, and grown in the germplasm repository of Northwest A\&F University, Shaanxi, China, under the same conditions with sufficient light and water (Fig. 1). The flowers opened during five developmental stages (from Stage 1 to Stage 5, i.e., from S1 to S5) as in the previous study of Shi et al. (2015). The petals were picked from five different individuals of $\mathrm{Pl}$ and $\mathrm{Pd}$ during five developmental stages and immediately frozen in liquid nitrogen for the total content measurement of pigments. To measure the pigment contents and conduct gene separately detached at the fully opened stage with exposed anther and immediately frozen in liquid nitrogen and stored at $-80{ }^{\circ} \mathrm{C}$ before analysis. In addition, petals at the fully opened stage were separately detached and used immediately for the morphological and anatomical observations, protoplast preparation, and $\mathrm{pH}$ and metal ion measurements. expression analyses, the petal samples were

Petal color measurement. The petal color at the fully opened stage was determined by comparison with the Royal Horticultural Society Color Chart (RHSCC) and then measured with a chroma meter (CR-400; Konica Minolta Sensing, Inc., Osaka, Japan) using five color parameters, including the indices of lightness $\left(\mathrm{L}^{*}\right)$, chromatic components $\left(\mathrm{a}^{*}, \mathrm{~b}^{*}\right)$, brightness $\left(\mathrm{C}^{*}\right)$, and hue angle (h) (Zhang et al., 2007). Six replications were recorded. The mean values and SDS were obtained.

Microscopic observations of the epidermal cells and transverse sections. According to the method of Shi et al. (2017), fresh petals of Pl and Pd flowers at the fully opened stage were cross-sectioned with the help of razor blade. The upper and lower epidermal layers were peeled off using a razor blade. The layers were placed onto a glass slide with a drop of water and then immediately observed under a light microscope (BX43; Olympus, Tokyo, Japan) equipped with a DS cooled camera head with FNIS-Elements image processing software.
A

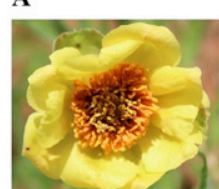

E

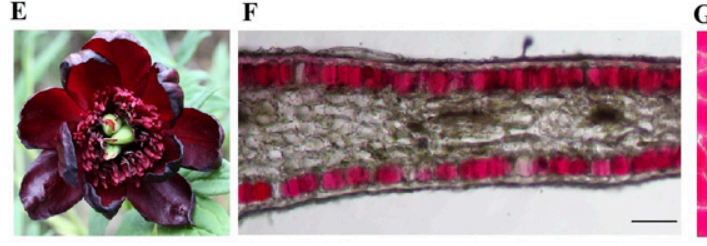

B

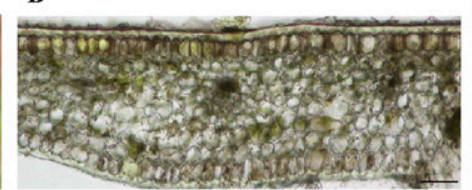

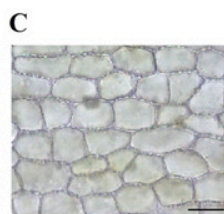

G

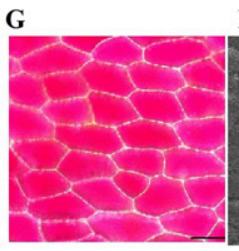

D

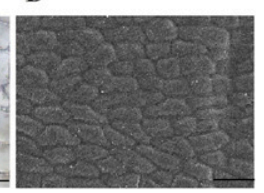

H

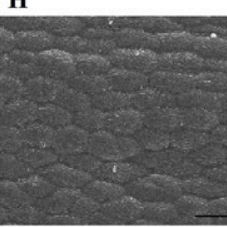

Fig. 1. Cellular features of a yellow-flowered individual (Pl) and a purple-red-flowered individual (Pd) of Paeonia delavayi. Fully opened flowers of $\mathrm{Pl}(\mathbf{A})$ and $\mathrm{Pd}(\mathbf{E})$ of $P$. delavayi. Cross sections of petals of $\mathrm{Pl}(\mathbf{B})$ and $\mathrm{Pd}(\mathbf{F})$ of $P$. delavayi. Epidermal cells of upper petals: epidermal cells of $\mathrm{Pl}(\mathbf{C})$ and $\mathrm{Pd}(\mathbf{G})$ petals. Scanning electron micrograph of epidermal cells from the outer epidermis of petals of P1 (D) and $\mathrm{Pd}(\mathbf{H})$. Bars $=100 \mu \mathrm{m}$.
Scanning electron microscopy observations. The Pl and Pd petals of $P$. delavayi were spliced into $5 \times 5 \mathrm{~mm}$ blocks, fixed in FAA buffer (38\% methanol, $5 \mathrm{~mL}$; acetic acid, $5 \mathrm{~mL}$; $70 \%$ ethanol, $90 \mathrm{~mL}$ ) under vacuum pressure for $30 \mathrm{~min}$, and then incubated at $4{ }^{\circ} \mathrm{C}$ overnight. Next, the fixed petals were dehydrated in an ascending aqueous ethanol series (30, 50, 70, 80, 90, and 100\%), followed by $100 \%$ acetone and then treated twice with isopentyl acetate for $30 \mathrm{~min}$. Finally, the samples were dried using a $\mathrm{CO}_{2}$ supercritical drying technique (K850; Quorum, England), mounted on a specimen stub, and sputter-coated with gold before examination in a scanning electron microscope (SU-3400N; Hitachi Ltd., Japan).

Preparation of free protoplasts. Free protoplast was prepared from $\mathrm{Pl}$ and $\mathrm{Pd}$ fresh petals at the fully opened stage according to Qi et al. (2013) with slight modifications. The middle part of fresh petals was cut into $1 \mathrm{~mm}$ filaments using a blade and then placed into $20 \mathrm{~mL}$ of enzymolysis solution $(0.3 \mathrm{~g}$ of $1.5 \%$ $(\mathrm{w} / \mathrm{v})$ cellulase $\mathrm{R}-10,0.06 \mathrm{~g}$ of $0.3 \%(\mathrm{w} / \mathrm{v})$ macerozyme R-10, $2.1869 \mathrm{~g}$ of $600 \mathrm{~mm}$ mannitol, $0.04264 \mathrm{~g}$ of $10 \mathrm{~mm} \mathrm{MES,} 8 \mu \mathrm{L}$ of $1 \mathrm{mM} \mathrm{CaCl}_{2}, 7 \mu \mathrm{L}$ of $5 \mathrm{~mm} \beta$-mercaptoethanol, and $0.02 \mathrm{~g}$ of $0.1 \%(\mathrm{w} / \mathrm{v}) \mathrm{BSA}$; $\mathrm{pH} 5.7)$. After vacuum infiltration for $30 \mathrm{~min}$ without shaking, the enzymolysis solution with petal strips was shaken for $1 \mathrm{~h}$ at $80 \mathrm{rpm}$ and $25{ }^{\circ} \mathrm{C}$ to release the protoplasts. The reaction mixture containing free protoplasts was filtered through a $75-\mu \mathrm{m}$ nylon mesh and washed with buffer $(0.017 \mathrm{~g}$ of $4 \mathrm{~mm}$ MES-Tris, $2.1869 \mathrm{~g}$ of $600 \mathrm{~mm}$ mannitol, and $0.0298 \mathrm{~g}$ of $20 \mathrm{mM} \mathrm{KCl}$; pH 5.7), then centrifuged in $20-\mathrm{mL}$ round-bottomed tube. As much supernatant liquid as possible was removed, and the protoplast pellet was resuspended in $2 \mathrm{~mL}$ of fresh buffer by gentle swirling. The centrifugal separation/resuspension procedure was repeated two times, and the released protoplasts were examined under a microscope (BX43; Olympus, Tokyo, Japan).

Table 1. Primers used for quantitative real-time polymerase chain reaction analysis.

\begin{tabular}{|c|c|c|c|}
\hline Gene name & Unigene ID & Forward primer sequence $\left(5^{\prime}-3^{\prime}\right)$ & Reverse primer sequence $\left(5^{\prime}-3^{\prime}\right)$ \\
\hline$\overline{\mathrm{CHS}}$ & Unigene45464_All & CAATCATGGCAATTGGAACA & GCTCGACCTTGTCCTCACTG \\
\hline $\mathrm{CHI}$ & CL7622.Contig1_All & AACAACTTTCCGAGGCTGTG & CCTAGCTGCCAAACTCTGCT \\
\hline DFR & CL1376.Contig6_All & GATGCCGAAACCGTGTGT & AAATGCTTCACCTTCCTCGT \\
\hline $\mathrm{F} 3 \mathrm{H}$ & CL2583.Contig1_All & CTTCGCTCTACCGCCTGAT & CAATCTCGCACAGCCTCTC \\
\hline $3 \mathrm{GT}$ & CL4890.Contig2_All & GGGAGATAGAGAAAGGAGTGAGG & GAAGAACCACCATCCACCAG \\
\hline $5 \mathrm{GT}$ & Unigene16716_All & ATCAAGCCACGAATGCCAAGC & АATCACCACСТТТССССАССТС \\
\hline $7 \mathrm{GT}$ & CL11011.Contig1_All & CCTATCCGACACAAGGCAAT & TACGCAGAGATGCTGGTTG \\
\hline THC2'GT & Unigene18441_All & CATCTTGTATCGGCAGTGGA & TCTGTCCTGGGTTGAGAAGG \\
\hline FNS & CL8830.Contig1_All & TTCATCCCAGCACACACACT & ACCCTCACACGACTCCAAGA \\
\hline FLS & Unigene8606_All & AGAAGCAGTGGGTGGTGAAG & ATGGTGAGGGTGGACAAATC \\
\hline ANS & Unigene13390_All & ACCAAGAGGCTGGGAAGATT & CAGGGAAGACAAGGTGGAAG \\
\hline
\end{tabular}

Table 2. Petal colors and color parameters of Paeonia delavayi.

\begin{tabular}{|c|c|c|c|c|c|c|c|}
\hline \multirow[b]{2}{*}{ Materials } & \multirow[b]{2}{*}{ Petal color } & \multirow[b]{2}{*}{ RHSCC } & \multicolumn{5}{|c|}{ CIEL $* a * b *$ color coordinates } \\
\hline & & & $\mathrm{L}^{*}$ & $\mathrm{a}^{*}$ & $\mathrm{~B}^{*}$ & $\mathrm{c}^{*}$ & $h$ \\
\hline$\overline{\mathrm{P} 1^{\mathrm{z}}}$ & Yellow & $4 \mathrm{~A}$ & $93.256 \pm 0.035$ & $43.526 \pm 0.014$ & $56.188 \pm 0.021$ & $94.8 \pm 0.038$ & $90.418 \pm 0.032$ \\
\hline $\mathrm{Pd}^{\mathrm{y}}$ & Deep purple & $185 \mathrm{~A}$ & $48.565 \pm 0.016$ & $81.295 \pm 0.041$ & $15.061 \pm 0.008$ & $3.949 \pm 0.011$ & $47.208 \pm 0.015$ \\
\hline
\end{tabular}

${ }^{\mathrm{z}} \mathrm{P}$, yellow-colored flower of $P$. delavayi.

${ }^{\mathrm{y}} \mathrm{Pd}$, purple-red flower of $P$. delavayi. 
Metal ions measurement. The petals of $\mathrm{Pl}$ and Pd flowers at fully opened stage were rinsed in sterile water and then placed in a drying oven at $105^{\circ} \mathrm{C}$ for $30 \mathrm{~min}$, followed by $80{ }^{\circ} \mathrm{C}$ for $6 \mathrm{~h}$. Dried petals were finely ground to a powder, and then, $2 \mathrm{mg}$ of dried powder was digested in $5 \mathrm{~mL} \mathrm{HNO}_{3}$ and $1 \mathrm{~mL}$ $\mathrm{H}_{2} \mathrm{O}_{2}$ and then treated in a high performance microwave digestion unit (ICAP Qc; Thermo Fisher Scientific, Waltham, MA) using the procedure of Qi et al. (2013). After complete digestion and acid removal, the samples were diluted with double-distilled water and then analyzed the contents of metal ions using ICP-MS (ICAP Qc; Thermo Fisher Scientific). The mean values and SDs were obtained from three biological replications.

Petal vacuolar $\mathrm{pH}$ measurement. To measure the vacuolar $\mathrm{pH}, 2 \mathrm{~g}$ of fresh petals of the $\mathrm{Pl}$ and Pd flowers at the fully opened stage was ground in liquid nitrogen and centrifuged at $18,407 g_{\mathrm{n}}$ for $5 \mathrm{~min}$. The $\mathrm{pH}$ of the supernatant was measured using a flat $\mathrm{pH}$ tester (pH5F; Shanghai Sanxin Instrument Corporation, China) at $25{ }^{\circ} \mathrm{C}$ (Zhao et al., 2016). The average $\mathrm{pH}$ and sDs of each flower color was calculated from 10 replications.

Flavonoid and anthocyanidins analysis. The petals of Pd and Pl flowers at five different development stages were lyophilized using the lyophilizer (LGJ-25C; Beijing Four-ring Science Instrument Plant Corporation, China). Then, a total of $10 \mathrm{mg}$ of lyophilized petal powder from 10 individual $\mathrm{Pl}$ and Pd flowers were extracted in $1 \mathrm{~mL}$ of $0.1 \%$ acetic acid/methanol solution at $4{ }^{\circ} \mathrm{C}$ overnight and then centrifuged for $10 \mathrm{~min}$ at $10,000 \mathrm{rpm}$. The supernatant was collected and dried with a vacuum centrifuge concentrator (CV100-DNA; Aijimu, Beijing, China). The identification and quantification of flavonoid and anthocyanin compounds were performed with an ultrahigh performance liquid chromatography-mass spectrometry system (UPLC-MS/MS; Waters, Milford, MA) coupled to a triple quadrupole mass spectrometry system (XEVO ${ }^{\circledR}$-TQ; Waters) with electrospray ionization (ESI) based on previous methods (Veberic et al., 2015) with modifications. The anthocyanin and flavonoid contents

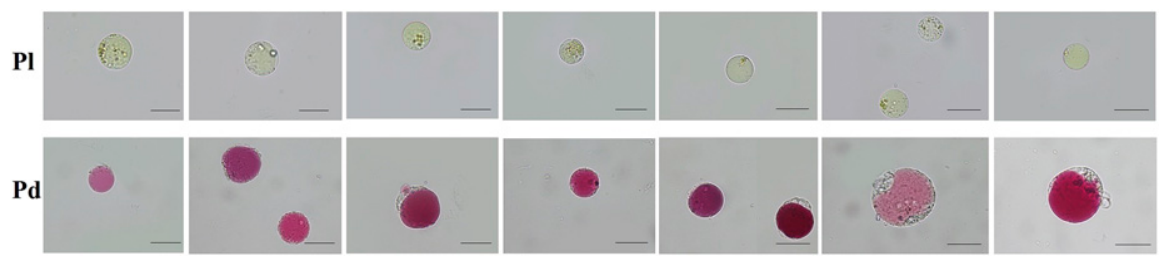

Fig. 2. Protoplasts from yellow-flowered individual (Pl) and purple-red-flowered individual (Pd) of

were measured semiquantitatively according to the method reported by Shi et al. (2017). The mean values and sDs were obtained from three biological replications.

Quantitative real-time polymerase chain reaction ( $q R T-P C R$ ) analysis. Total RNA was extracted from the fully opened petals of the Pl and Pd flowers using Trizol (Invitrogen, Carlsbad, CA). After verifying the RNA purity and integrity, $1 \mathrm{mg}$ of total RNA was reverse-transcribed to first-strand cDNA with a PrimeScript RT reagent kit (Takara, Otsu, Japan). The qRT-PCR assay was conducted using a fluorescent intercalating dye on a Light Cycler 480 with SYBR Green I Master Mix (Roche, Mannheim, Germany), following the procedure of Shi et al. (2017). Specific primers were designed using Primer Premier software (Table 1). The relative expression levels of genes in the petals of the $\mathrm{Pl}$ and Pd flowers were normalized to the $T U B$ gene expression level in the same sample. All reactions were conducted with three biological replications and three technical replications.

\section{Results}

Color indices. According to the RHSCC, the colors of $\mathrm{Pd}$ and $\mathrm{Pl}$ flowers were purplered (185A) and yellow (4A), respectively (Fig. 1A and E; Table 2). The higher $\mathrm{L}^{*}$ value in $\mathrm{Pl}$ indicated that $\mathrm{Pl}$ petals had a lighter color than those of $\mathrm{Pd}$. The lower $\mathrm{a}^{*}$ value in $\mathrm{Pl}$ than in $\mathrm{Pd}$ indicated that the green level was higher in $\mathrm{Pl}$, whereas the redness level was higher in Pd. The higher $\mathrm{b}^{*}$ value in $\mathrm{Pl}$ than in Pd indicated that the yellow level was higher in $\mathrm{Pl}$, whereas the blue level was higher in $\mathrm{Pd} . \mathrm{C}^{*}$ represents the saturation of the color, and the higher $\mathrm{C}^{*}$ value for $\mathrm{Pl}$ than for Pd indicated that $\mathrm{Pl}$ had a much more vivid color, whereas $\mathrm{Pd}$ had a grayer color. The hue angle $(h)$ of $\approx 90^{\circ}$ in the Pl petals represented yellow and the $h$ of $\approx 47^{\circ}$ in the $\mathrm{Pd}$ petals mean red.

Anatomical analysis. In $\mathrm{Pl}$, the yellow cells were located in upper epidermis (Fig. 1). In addition, sporadically colored Paeonia delavayi. Bars $=30 \mu \mathrm{m}$.

Table 3. Concentration of metal elements in Paeonia delavayi petals.

\begin{tabular}{|c|c|c|c|c|c|c|c|c|}
\hline \multirow[b]{2}{*}{ Materials } & \multicolumn{8}{|c|}{ Concn of metal ions $\left(\mathrm{mg} \cdot \mathrm{kg}^{-1}\right)$} \\
\hline & $\mathrm{Ca}$ & $\mathrm{Mg}$ & $\mathrm{Fe}$ & $\mathrm{Zn}$ & $\mathrm{Cu}$ & $\mathrm{Al}$ & $\mathrm{Cd}$ & $\mathrm{Mn}$ \\
\hline$\overline{\mathrm{P} l^{\mathrm{z}}}$ & $1,614.56 \pm 45.712$ & $1,088.47 \pm 27.655$ & $51.185 \pm 5.075$ & $35.308 \pm 3.290$ & $8.766 \pm 0.420$ & $37.170 \pm 3.648$ & $0.024 \pm 0.002$ & $6.140 \pm 0.312$ \\
\hline $\mathrm{Pd}^{\mathrm{y}}$ & $1,636.22 \pm 47.236$ & $1,075.22 \pm 25.761$ & $64.497 \pm 6.434$ & $39.271 \pm 3.872$ & $8.166 \pm 0.401$ & $55.806 \pm 5.512$ & $0.028 \pm 0.003$ & $6.633 \pm 0.325$ \\
\hline
\end{tabular}

${ }^{\mathrm{z}} \mathrm{Pl}$, yellow-colored flower of $P$. delavayi.

${ }^{\mathrm{y}} \mathrm{Pd}$, purple-red flower of $P$. delavayi. cells were in the palisade mesophyll and spongy mesophyll (Fig. 1B). In $\mathrm{Pd}$, the colored cells were primarily located in the upper and lower epidermis and not in the palisade mesophyll and spongy mesophyll (Fig. 1F). Notably, the degree of pigmentation varied slightly between the upper and lower epidermis. To further clarify the mechanism for the various flower colorations of $P$. delavayi, the colored protoplasts were analyzed. A large amount of yellow protoplasts and a small amount of colorless protoplasts were located in the yellow-colored Pl petals. However, the purple-red-colored flower was composed of a mixture of purple, red, and pink protoplasts (Fig. 2). These results were in line with the observations from transverse sections.

The shape of the epidermal cells can influence the visual effect of the color. In this study, the Pl cells were subrotund and flat, whereas the $\mathrm{Pd}$ cells were irregularly polygon-shaped and bulging (Fig. 1C, D, G, and $\mathrm{H}$ ). These findings suggested that the various flower colors of $P$. delavayi were partly associated with different epidermal cell shapes.

Metal ions and $\mathrm{pH}$ analysis. To determine whether metal ions had an effect on flower color formation of $P$. delavayi, eight metal elements ( $\mathrm{Ca}, \mathrm{Mg}, \mathrm{Fe}, \mathrm{Zn}, \mathrm{Cu}, \mathrm{Al}, \mathrm{Cd}$, and $\mathrm{Mn})$ related to color formation were measured using inductively coupled plasma mass spectrometry in $\mathrm{Pl}$ and $\mathrm{Pd}$ petals (Yoshida et al., 2009a, 2009b; Qi et al., 2013). As shown in Table 3, the two most abundant metal ion elements in the $\mathrm{Pl}$ and $\mathrm{Pd}$ petals were $\mathrm{Ca}$ and $\mathrm{Mg}$, which were followed by $\mathrm{Fe}$ and Al. Except for the contents of Fe and Al, which were much higher in $\mathrm{Pd}$ than in $\mathrm{Pl}$, the other metal elements did not show differences between the $\mathrm{Pl}$ and $\mathrm{Pd}$ petals.

Besides, the $\mathrm{pH}$ of the $\mathrm{Pl}$ and $\mathrm{Pd}$ petals was $5.76 \pm 0.049$ and $4.61 \pm 0.015$, respectively (Table 4), and the difference was significant. Thus, the sap $\mathrm{pH}$ might contribute to the formation of different flower colors.

Qualitative and quantitative analysis of pigments. For tree peony, flavonoids, particularly anthocyanins, are responsible for various flower colors such as white, yellow, red, pink, purple, and so on (Hosoki et al., 1991; Wang et al., 2001a, 2001b, 2005; Zhang et al., 2007; Zhou et al., 2011). The pigment composition and content were measured in the fully opened flowers of $\mathrm{Pl}$ and $\mathrm{Pd}$ using UPLC-MS. According to the ultravioletvisible absorption characteristics, anthocyanins, flavonol, and chalcone were detected under the wavelength of 520 and $350 \mathrm{~nm}$, respectively (Fig. 3). At $520 \mathrm{~nm}$, no anthocyanins were found in $\mathrm{Pl}$, whereas five 


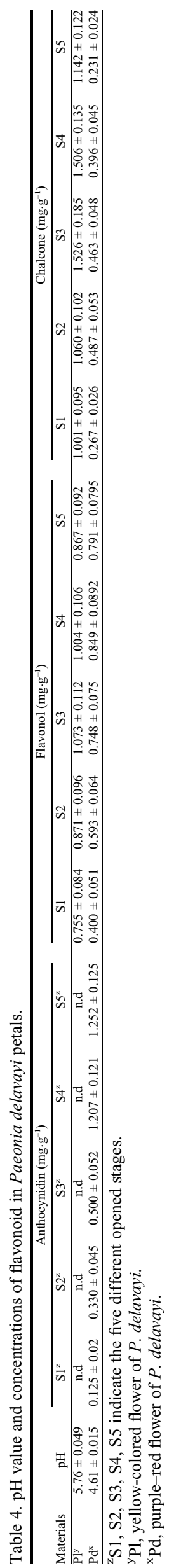

obvious peaks (a1, a2, a3, a4, and a5) were detected in $\mathrm{Pd}$, among which a3 and a5 were the highest. On the basis of the maximum absorption wavelength $(\lambda \max )$ and the fragment ions $(\mathrm{m} / \mathrm{z})$, the five peaks at $520 \mathrm{~nm}$ were presumed to be cyanidin 3, 5-di- $O$ glucoside (Cy3G5G), Pn3G5G, cyanidin 3$O$-glucoside $(\mathrm{Cy} 3 \mathrm{G})$, cyanidin 3 -arabinoside (Cy3A), and peonidin 3-O-glucoside (Pn3G), respectively (Table 5). Meanwhile, we detected many of the same but also different flavonoids at $350 \mathrm{~nm}$ in these two flower types (Fig. 3; Tables 5 and 6). The same flavonoids identified in these two flowers included a $\mathrm{Qu}$ derivative, $\mathrm{Km} \mathrm{3,} \mathrm{7-di-O-}$ hexoside, Is 3- $O$-glucoside, and chalcononaringenin $2^{\prime}$ - $O$-glucoside (chalcone 2 'G). Is 3 , 7-di- $O$-glucoside, luteolin $(\mathrm{Lu})$ 7-O-glucoside, Ap 7-O-neohesperidoside, and $\mathrm{Ch}$ 7-Oglucoside were only detected in $\mathrm{Pl}$, whereas the $\mathrm{Pd}$ petals included $\mathrm{Km} 3$ - $O$-glucoside, Is 3-O-gallcylglucoside, and $\mathrm{Km}$ 7-O-glucoside (Tables 5 and 6). These results indicated that the Ap-, $\mathrm{Ch}$-, and 7-O-glucoside flavonols were the primary copigments responsible for the yellow coloration and the anthocyanins were responsible for the purple-red coloration.

Concerning the pigment content, chalcone 2 ' $\mathrm{G}$ accumulated most abundantly in $\mathrm{Pl}$ and was 5-fold higher than that in $\mathrm{Pd}$. Is 3$\mathrm{O}$-glucoside and $\mathrm{Lu} 7-\mathrm{O}$-glucoside were also abundantly accumulated in $\mathrm{Pl}$ at $\approx 348$ and $337 \mu \mathrm{g} \cdot \mathrm{g}^{-1}$, respectively; however, the contents of Ap 7-O-neohesperidoside and $\mathrm{Ch} 7-$ $O$-glucoside were low at 20 and $53 \mu \mathrm{g} \cdot \mathrm{g}^{-1}$, respectively (Table 6). For $\mathrm{Pd}$, the most abundant anthocyanin was Cy3G $\left(631 \mu \mathrm{g} \cdot \mathrm{g}^{-1}\right)$, followed by Pn3G (303 $\left.\mu \mathrm{g} \cdot \mathrm{g}^{-1}\right)$, Pn3G5G $\left(160 \mu \mathrm{g} \cdot \mathrm{g}^{-1}\right)$, and Cy3G5G $\left(102 \mu \mathrm{g} \cdot \mathrm{g}^{-1}\right)$. In addition, Cy3 A was hardly detectable $\left(8 \mu \mathrm{g} \cdot \mathrm{g}^{-1}\right)$. Interestingly, among the identified flavonols in $\mathrm{Pd}$, chalcone $2{ }^{\prime} \mathrm{G}$ was the most abundant $\left(395 \mu \mathrm{g} \cdot \mathrm{g}^{-1}\right)$, followed by Qu 7-Oglucoside $\left(228 \mu \mathrm{g} \cdot \mathrm{g}^{-1}\right)$ and Is 3-O-glucoside $\left(156 \mu \mathrm{g} \cdot \mathrm{g}^{-1}\right)$ (Table 5). The total content of anthocyanins was rising during development of Pd flowers, whereas the total contents of flavonols and chalcone accumulated without any rules during $\mathrm{Pd}$ flower development. However, the total contents of flavonols and chalcone in $\mathrm{Pl}$ were always higher than those in Pd at all the developmental stages (Table 4).

Expression analysis of key flavonoid biosynthetic genes. To further investigate the effect of the flavonoid biosynthetic genes on the various flower colorations of $P$. delavayi, qRT-PCR was conducted to test the expression patterns of 12 related structural genes in fully opened petals of $\mathrm{Pl}$ and $\mathrm{Pd}$ (Fig. 4; Table 1). The 11 genes were $C H S$, CHI, DFR, F3H, FNS, FLS, anthocyanin 3-O-glycosyltransferase $(3 G T)$, anthocyanin 5-O-glycosyltransferase $(5 G T), 7 G T, T H C$, and $A N S$, which are involved in flower pigmentation of $P$. delavayi (Shi et al., 2015). CHI, F3H, FNS, FLS, 7GT, and THC were significantly highly expressed in $\mathrm{Pl}$ relative to Pd. In particular, FNS was barely detected in Pd (Fig. 4). Moreover, the expression patterns of these genes were in agreement with the accumulation levels of the corresponding flavones and flavonols. However, CHS, $D F R, 3 G T, 5 G T$, and $A N S$ were expressed strongly in the Pd petals (Fig. 4). Among these genes, the expression of $C H S, D F R$, and $A N S$, which are the key enzymes for anthocyanin synthesis (Tanaka and Ohmiya, 2008; Suzuki et al., 2016), was significantly higher in the Pd petals than in the $\mathrm{Pl}$ petals. These results demonstrated that the different flower colorations of $P$. delavayi were caused by the different expression patterns of different flavonoid biosynthetic genes, which led to the corresponding differences in the accumulation levels of different pigments.

\section{Discussion}

Paeonia delavayi is a special wild tree peony species and has the most previous resource of yellow flowers. The flower coloration involves many factors, such as the petal structure, pigment type and distribution, vacuolar $\mathrm{pH}$, and metal ion complexation (Zhao and Tao, 2015). The shape of epidermal cells affects the pigmentation, with conical cells leading to darker flower color and enhanced color saturation (Noda et al., 1994). In the present study, the petal epidermal cells were different between the yellowcolored Pl and purple-red-colored Pd. As expected, the epidermal cells of Pd were bulging and, therefore, had darker color. Notably, in previous work, we found that the shapes of the petal epidermal cells were different between different tree peony species, with those of the dark purple-colored petals of $P$. rockii elongated and explanate and those of purple-red-colored individuals of $P$. delavayi irregularly polygon-shaped and bulging (Shi et al., 2017). Differences in the shape of the petal epidermal cells also affect the texture of petals and ultimately affect pollinator attraction (Glover, 2000). In wild populations, bees are the most important pollinators for $P$. delavayi, whereas abiotic factors are the most important for $P$. rockii (Li et al., 2013b)

Moreover, anthocyanin can change in relation to the cell sap $\mathrm{pH}$, which affects flower color (Quintana et al., 2007). Because of an increased $\mathrm{pH}$, the reddish-purple petals of I. tricolor cv. Heavenly Blue change to blue (Asen et al., 1977). The same results are found in Petunia hybrid (Griesbach, 1996). The stability of anthocyanins is greatly influenced by $\mathrm{pH}$ and decreases with an increase in $\mathrm{pH}$ (Zhao et al., 2005), whereas flavone and flavonol tend to become more yellow as the vacuolar acidity weakens (Fu et al., 2013). Similarly, the $\mathrm{pH}$ values in the yellow-colored individuals of $P$. delavayi were much higher than those in the purplered-colored individuals. Thus, $\mathrm{pH}$ might be related to the different flower coloration of $P$. delavayi. Metal ions affect the pigment structure and thus the flower color. The pale yellow flower of Tagetes patula changes to golden yellow when treated with alums, to deep orange when treated with $\mathrm{Cr}$, and to brown when treated with $\mathrm{Cu}$, and these changes are considered to be the result of 


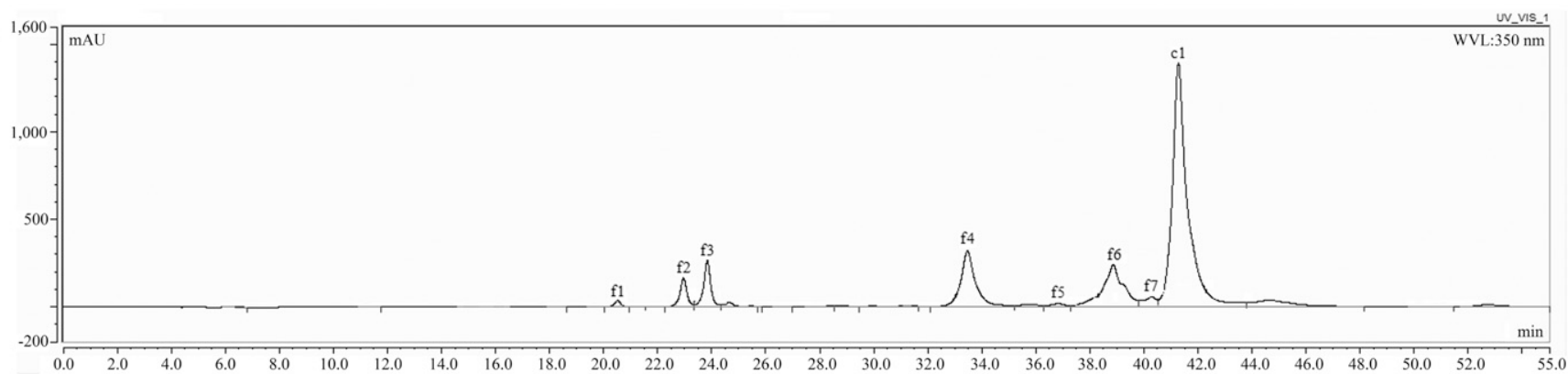

B

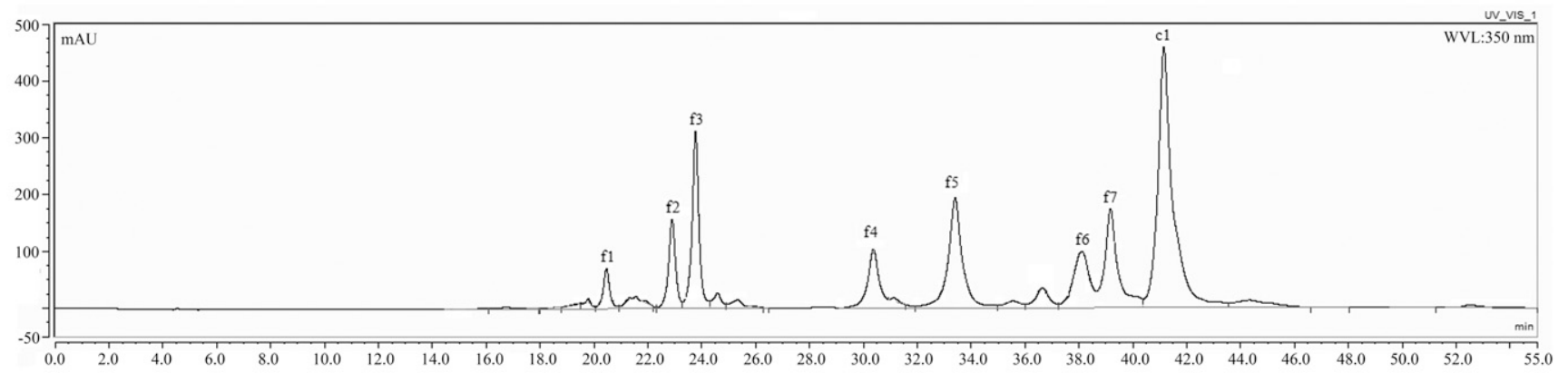

C

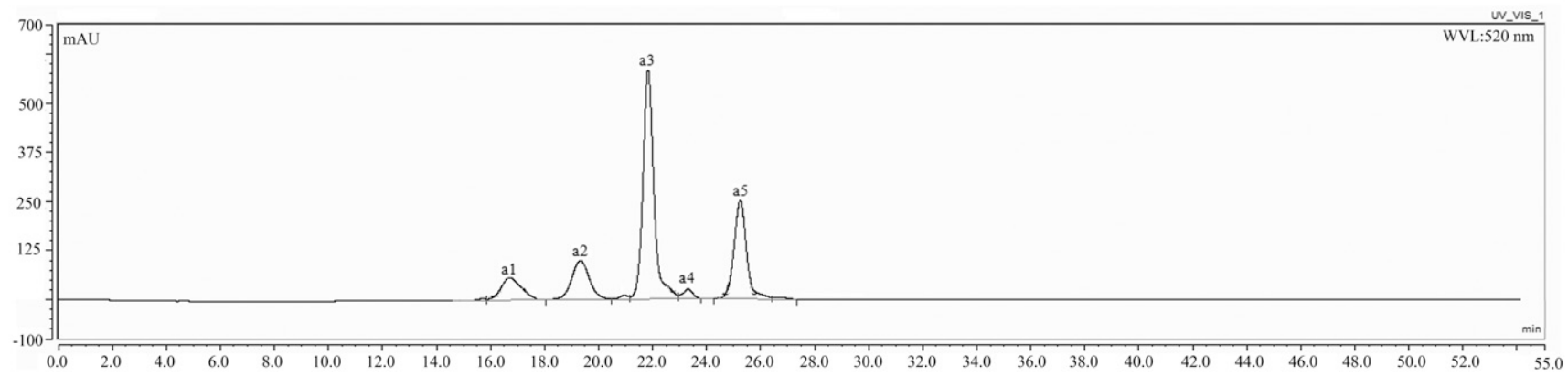

Fig. 3. Ultrahigh performance liquid chromatography (UPLC) chromatograms of yellow-colored individual and purple-red-colored individual of Paeonia delavayi flavonoids at $350 \mathrm{~nm}$ and anthocyanins at $525 \mathrm{~nm}$ at the fully opened stage (S5). (A) UPLC chromatograms of yellow-colored individual; (B) UPLC chromatograms of purple-red-colored individual at $350 \mathrm{~nm}$; (C) UPLC chromatograms of purple-red-colored individual at $520 \mathrm{~nm}$; f1-f7 indicated identified flavonoids compositions; a1-a4 indicates identified anthocyanin compositions.

a shift between flavonoids and $\mathrm{Qu}(\mathrm{Li}$ et al., 2013a). $\mathrm{Mg}^{2+}$ can increase the content of anthocyanin, thereby enriching flower colors $(15 \%$ to $70 \%)$, such as in the red flower of Anigozanthos flavidus, the blue bracts of Limonium sinuatum, the pink flowers of Gypsophila elegans, and the blue flowers of Aconitum carmichaelii (Nissan-Levi et al., 2007). The blue color of H. macrophylla is derived from $\mathrm{Al}^{3+}$-complexed anthocyanin and copigments (Ito et al., 2009; Takeda et al., 2005; Yoshida et al., 2003), whereas the sky-blue color of Meconopsis grandis and Centaurea cyanus is caused by $\mathrm{Mg}^{2+}$ - and $\mathrm{Fe}^{3+}$ - complexed anthocyanins (Kondo et al., 1994, 1998; Shiono et al., 2005; Takeda et al., 2005; Yoshida et al., 2006; Yoshida and Negishi, 2013). The blue coloration at the bottom of the inner perianth of $T$. gesneriana is attributed to $\mathrm{Fe}^{2+}$ (Momonoi et al., 2009; Shoji et al., 2010). In red and yellow petals of Paeonia lactiflora, $\mathrm{K}, \mathrm{Ca}, \mathrm{Mg}, \mathrm{Mn}$, and $\mathrm{Zn}$ were abundant and showed significant correlation coefficient with the color indice $h$ (Zhao et al., 2017). Although $\mathrm{Ca}, \mathrm{Mg}, \mathrm{Fe}$, and $\mathrm{Al}$ were the most abundant metal ions in the Pd and Pl petals, only Fe and $\mathrm{Al}$ showed

Table 5. Contents of identified flavonoids and anthocyanins in purple-red-colored individual petals of Paeonia delavayi at the fully opened stage (S5) $\left(\mu \mathrm{g} \cdot \mathrm{g}^{-1}\right)$.

\begin{tabular}{lllcr}
\hline No. $^{z}$ & \multicolumn{1}{c}{ Identification } & $\Lambda \max (\mathrm{nm})$ & ESI- $(+)-M S(\mathrm{~m} / \mathrm{z})$ & Content $\left(\mu \mathrm{g} \cdot \mathrm{g}^{-1}\right)$ \\
\hline f1 & Km 3-O-glucoside & 347,254 & 287,449 & $45.056 \pm 0.041$ \\
f2 & Km 3,7-di-O-hexoside & 269 & $287,449,633$ & $80.938 \pm 0.071$ \\
f3 & Qu 3,7-di-O-glucoside & 256 & $301,463,641$ & $139.174 \pm 0.121$ \\
f4 & Qu 7-O-glucoside & 256 & 303,487 & $228.891 \pm 0.150$ \\
f5 & Is 3-O-gallcylglucoside & 348 & 317,653 & $68.293 \pm 0.058$ \\
f6 & Km 7-O-glucoside & 266 & 287,471 & $130.265 \pm 0.116$ \\
f7 & Is 3-O-glucoside & 254 & 317,501 & $156.024 \pm 0.139$ \\
c1 & chalcone 2 'G & 365 & 273,457 & $395.855 \pm 0.311$ \\
a1 & Cy3G5G & 509,287 & 449,287 & $102.196 \pm 0.083$ \\
a2 & Pn3G5G & 515,287 & $301,463,625$ & $160.076 \pm 0.130$ \\
a3 & Cy3G & 509,287 & 287,449 & $631.384 \pm 0.561$ \\
a4 & Cy3A & 509,287 & 287,419 & $8.592 \pm 0.008$ \\
a5 & Pn3G & 515,287 & 301,463 & $303.992 \pm 0.256$ \\
\hline
\end{tabular}

${ }_{\mathrm{z}} \mathrm{f}-\mathrm{f} 7, \mathrm{c} 1$, and a1-a5 indicate the order of the identified flavonoids in yellow-colored flowers of P. delavayi.

large differences between $\mathrm{Pl}$ and $\mathrm{Pd}$, indicating that the different flower colors of $P$. delavayi might be related to $\mathrm{Fe}$ and $\mathrm{Al}$.

Previous studies showed that the opened purple flowers of $P$. delavayi mainly contained Pn3G5G, whereas the yellow flowers of $P$. delavayi primarily contain chalcone, $\mathrm{Km}, \mathrm{Qu}$, Is, Ch, and Ap-glycopyranoside
(Wang et al., 2001b; Zhou et al., 2011). As expected, in the present study, the primary pigments of $P$. delavayi were anthocyanin and chalcone. For Pd, anthocyanin, primarily $\mathrm{Cy}$ and Pn based, determined the flower color and flavones and flavonols generally acted as copigments to affect the flower color. Although the purple petals also contained 
Table 6. Contents of identified flavonoid in yellow-colored individual petals of Paeonia delavayi at the fully opened stage (S5) $\left(\mu \mathrm{g} \cdot \mathrm{g}^{-1}\right)$.

\begin{tabular}{|c|c|c|c|c|}
\hline No. & Identification & $\Lambda \max (\mathrm{nm})$ & ESI-(+)-MS (m/z) & Content $\left(\mu g \cdot g^{-1}\right)$ \\
\hline$\overline{\mathrm{fl}}$ & Qu derivative & 256 & 303 & $20.504 \pm 0.020$ \\
\hline f2 & Km 3,7-di-O-hexoside & 266 & $287,449,633$ & $85.282 \pm 0.079$ \\
\hline $\mathrm{f3}$ & Is 3,7-di-O-glucoside & 255 & $317,479,663$ & $136.611 \pm 0.121$ \\
\hline $\mathrm{f} 4$ & Lu 7-O-glucoside & 348 & 287,449 & $337.853 \pm 0.195$ \\
\hline f5 & Ap 7-O-neohesperidoside & 267 & 271,579 & $20.800 \pm 0.02$ \\
\hline f6 & Is 3-O-glucoside & 254 & 317,501 & $348.685 \pm 0.183$ \\
\hline f7 & Ch 7-O-glucoside & 346 & 301,463 & $53.496 \pm 0.051$ \\
\hline $\mathrm{c} 1$ & chalcone 2 ' $\mathrm{G}$ & 365 & 273,457 & $1,505.572 \pm 0.585$ \\
\hline
\end{tabular}

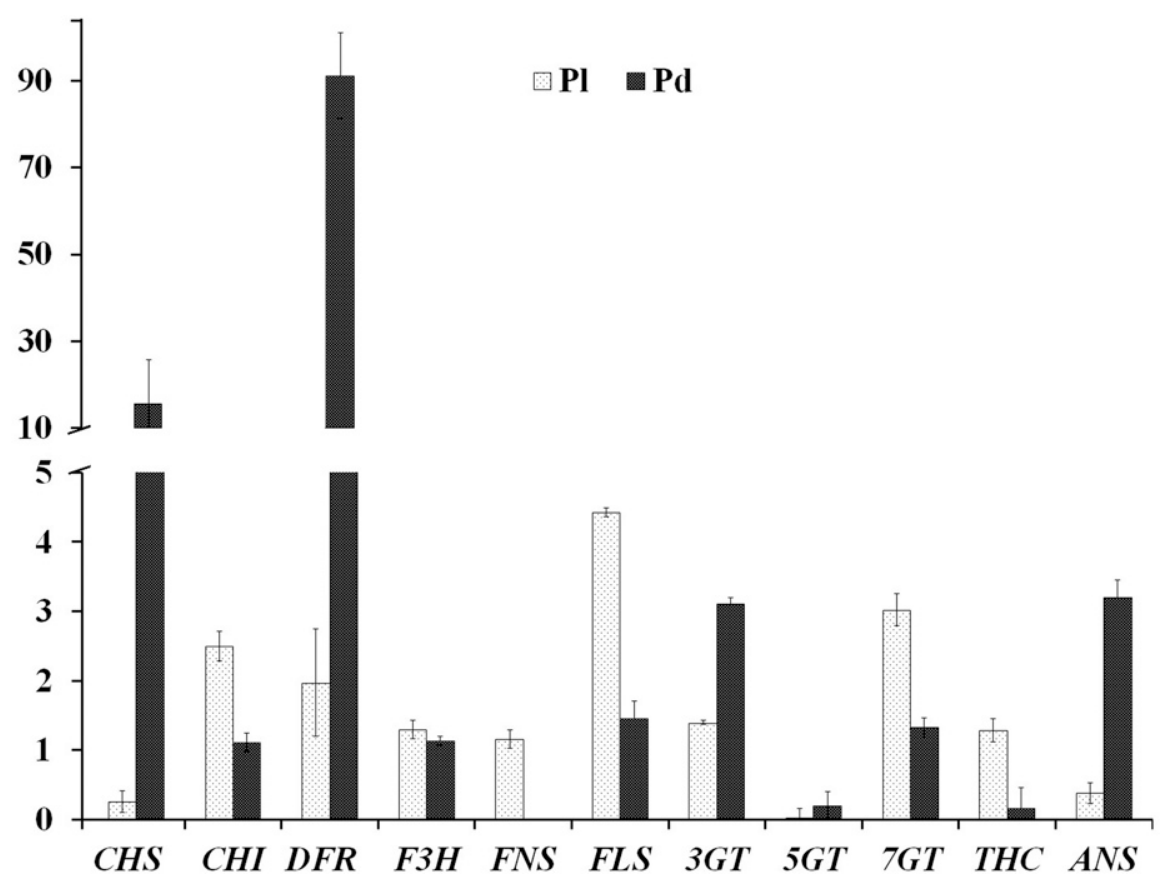

Fig. 4. Expression analyses of flavonoid biosynthetic genes in yellow-colored flower and purple-red flower of Paeonia delavayi by quantitative real-time polymerase chain reaction using total RNA from the petals at the fully opened stage (S5). Pl, yellow-colored flower of $P$. delavayi; Pd, purplered flower of $P$. delavayi. The TUB gene was used as an internal control, and relative transcript levels are presented as the means with SDS of three technical and three biological replications. CHS , chalcone synthase gene; $C H I$, chalcone isomerase gene; $F 3 H$, flavanone 3-hydroxylase; $D F R$, dihydroflavonol 4-reductase gene; $F N S$, flavonol synthase; $F L S$, flavonol synthase; $3 G T$, anthocyanin 3-O-glycosyltransferase; $5 G T$, anthocyanin 5-O-glycosyltransferase; $7 G T$, flavonoid 7-Oglycosyltransferase; THC, 2' 4' 6' 4-tetrahydroxychalcone $2^{\prime}$-glucosyltransferase; ANS, anthocyanidin synthase gene.

yellow chalcone, highly abundant anthocyanin covered the small amount of chalcone, resulting in a purple-red color. For $\mathrm{Pl}$, the main pigment was chalcone 2 ' $\mathrm{G}$, and Ap 7$O$-neohesperidoside and $\mathrm{Ch}$ 7-O-glucoside were copigments; thus, it appeared yellow, inconsistent with the report of yellow coloration in P. lactiflora (Zhao et al., 2014). The same glycoside had different modifications between $\mathrm{Pl}$ and $\mathrm{Pd}$. The hydroxylation modification of $\mathrm{Qu}$ and $\mathrm{Lu}$ can strengthen the red color and darken the flower color and the methylation modification of $\mathrm{Cy}$ and $\mathrm{Pn}$ can enhance the blue color. The copigment effect of flavones and flavonols in Pd was much higher than in $\mathrm{Pl}$ and increased the purple degree, which is consistent with results in Japanese tree peony (Sakata et al., 1995) and rhododendron (Asen et al., 1971). Correspondingly, the downstream structural genes and Ohmiya, 2008). These enzymes were significantly highly expressed in yellow petals, which was consistent with the flavonol and flavone production levels in Pl. Hence, the diversity of the flavone/flavonol and anthocyanin accumulation likely contributes to the different flower coloration of P. delavayi.

In conclusion, anatomical, chemical, and gene expression analyses indicated that the epidermal cell shape, vacuolar $\mathrm{pH}, \mathrm{Fe}$ and $\mathrm{Al}$ metal ions, and different pigments all affected the various flower colorations of $P$. delavayi. Therefore, the color variation of $P$. delavayi petals is likely dependent on the delicately controlled balance of these factors. Our results provide a substantial foundation for a full understanding of the mechanisms of $P$. delavayi flower pigmentation.

\section{Literature Cited}

Akashi, T., T. Aoki, and S. Ayabe. 1999. Cloning and functional expression of a cytochrome P450 cDNA encoding 2-hydroxyisoflavanone synthase involved in biosynthesis of the isoflavonoid skeleton in licorice. Plant Physiol. 121:821-828

Asen, S., R.N. Stewart, and K.H. Norris. 1971. Copigmentation effect of quercetin glycosides on absorbtion characteristics of cyaniding glycosides and color of Red Wing azalea. Phytochemistry 10:171-175.

Asen, S., R.N. Stewart, and K.H. Norris. 1977. Anthocyanin and $\mathrm{pH}$ involved in the color of 'Heavenly Blue' morning glory. Phytochemistry 16:1118-1119.

Fu, L.J., H. Li, L. Li, H. Yu, and L. Wang. 2013. Reason of flower color change in Lonicera japonica. Scientia Silvae Sin. 49:155-161.

Glover, B.J. 2000. Differentiation in plant epidermal cells. J. Expt. Biol. 51:497-505.

Griesbach, R.J. 1996. The inheritance of flower color in Petunia hybrida Vilm. J. Hered. 87:241-245.

Hong, D.Y. and K.Y. Pan. 1999. Taxonomical history and revision of Paeonia sect. Moutan (Paeoniaceae). Acta Phytotax Sin. 37:351-368.

Hong, D.Y. and K.Y. Pan. 2005a. Notes on taxonomy of Paeonia sect. Moutan dc. (Paeoniaceae). Acta Phytotax Sin. 43:169-177.

Hong, D.Y. and K.Y. Pan. 2005b. Additional taxonomy motes on Paeonia sect. Moutan (Paeoniaceae). Acta Phytotax Sin. 43:284-287.

Hong, D.Y. and K.Y. Pan. 2007. Paeonia cathayana D.Y. Hong \& K. Y. Pan, a new tree peony, with revision of $P$. suffruticosa ssp. yinpingmudan. Acta Phytotax Sin. 43:284 287.

Hong, D.Y., K.Y. Pan, and H. Yu. 1998. Taxonomy of the Paeonia delavayi complex (Paeoniaceae). Ann. Mo. Bot. Gard. 85:554-564.

Hosoki, T., M. Hamada, T. Kando, R. Moriwaki, and K. Inaba. 1991. Comparative study of anthocyanin in tree peony flowers. J. Jpn. Soc. Hort. Sci. 60:395-403.

Ito, D., Y. Shinkai, Y. Kato, T. Kondo, and K. Yoshida. 2009. Chemical studies on different color development in blue- and red-colored sepal cells of Hydrangea macrophylla. Biosci. Biotechnol. Biochem. 73:1054-1059.

Kondo, T., M. Ueda, and M. Isobe. 1998. A new molecular mechanism of blue color development with protocyanin, a supramolecular pigment from cornflower, Centaurea cyanus. Tetrahedron Lett. 49:8307-8310. 
Kondo, T., M. Ueda, H. Tamura, K. Yoshida, M. Isobe, and T. Goto. 1994. Composition of protocyanin, a self-assembled supramolecular pigment from the blue cornflower Centaurea cyanus. Angew. Chem. Intl. Ed. Engl. 33:978979.

Li, C.H., H. Du, L.S. Wang, Q.Y. Shu, Y.R. Zheng, and Y.J. Xu. 2009. Flavonoid composition and antioxidant activity of tree peony (Paeonia section Moutan) yellow flowers. J. Agr. Food Chem. 57:8496-8503.

Li, H., Y. Liu, J. Yue, and Q. Lou. 2013a. Study on the factors of flower color development in Tradescantia albiflora. Pratacult. Sci. 30:710 715.

Li, K., Y. Wang, B.Q. Zheng, X.T. Zhu, H.Z. Wu, and Q.Q. Shi. 2011. Pollen morphology of 40 Paeonia delavayi (Paeoniaceae) populations. J. Beijing For. Univ. 33:94-103.

Li, K., B.Q. Zheng, Y. Wang, and X. Guo. 2013b. Study on pollination biology of Paeonia delavayi (Peaoniaceae). Acta Hort. 977:175-181.

Marinova, K., K. Kleinschmidt, G. Weissenbock, and M. Klein. 2007. Flavonoid biosynthesis in barley primary leaves requires the presence of the vacuole and controls the activity of vacuolar flavonoid transport. Plant Physiol. 144:432-444.

Martens, S. and A. Mithöfer. 2005. Flavones and flavone synthases. Phytochemistry 66:2399-2407.

Momonoi, K., K. Yoshida, S. Mano, H. Takahashi, C. Nakamori, K. Shoji, A. Nitta, and M. Nishimura. 2009. A vacuolar iron transporter in tulip, TgVit1, is responsible for blue coloration in petal cells through iron accumulation. Plant J. 59:437-447.

Nissan-Levi, A., R. Ovadia, I. Foreer, and M. OrenShamir. 2007. Increased anthocyanin accumulation in ornamental plants due to magnesium treatment. J. Hort. Sci. Biotechnol. 82:481-487.

Noda, K., B.J. Glover, P. Linstead, and C. Martin. 1994. Flower colour intensitydepends on specialized cell shape controlled by a Myb-related transcription factor. Nature 369:661-664.

Park, N.I., H. Xu, X. Li, S.J. Kim, and S.U. Park. 2011. Enhancement of flavone levels through overexpression of chalcone isomerase in hairy root cultures of Scutellaria baicalensis. Funct. Integr. Genomics 11:491-496.

Qi, Y., Q. Lou, H. Li, J. Yue, Y. Liu, and Y. Wang. 2013. Anatomical and biochemical studies of bicolor flower development in Muscari latifolium. Protoplasma 250:1273-1281.

Quintana, A., J. Albrechtová, R.J. Griesbach, and R. Freyre. 2007. Anatomical and biochemical studies of anthocyanidins in flowers of Anagallis monelli L. (Primulaceae) hybrids. Scientia Hort. 112:413-421.

Sakata, Y., K. Toki, S. Tsunematsu, H. Nishikouri, and T. Johjima. 1995. Petal coloration and pigmentation of tree peony bred and selected in Daikon Island (Shimane Prefecture). J. Jpn. Soc. Hort. Sci. 64:351-357.

Schreiber, H.D., A.H. Jones, C.M. Lariviere, K.M. Mayhew, and J.B. Cain. 2011. Role of aluminum in red-to-blue color changes in Hydrangea macrophylla sepals. Biometals 24:1005-1015.

Schreiber, H.D., A.M. Swink, and T.D. Godsey. 2010. The chemical mechanism for $\mathrm{Al}^{3+}$ complexing with delphinidin: A model for the bluing of hydrangea sepals. J. Inorg. Biochem. 104:732-739.

Shi, Q., L. Li, X. Zhang, J. Luo, X. Li, L. Zhai, L. He, and Y. Zhang. 2017. Biochemical and comparative transcriptomic analyses identify candidate genes related to variegation formation in Paeonia rockii. Molecules 22:1364.

Shi, Q., L. Zhou, Y. Wang, K. Li, B.Q. Zheng, and K. Miao. 2015. Transcriptomic analysis of Paeonia delavayi wild population flowers to identify differently expressed genes involved in purple-red and yellow petal pigmentation. PLoS One 10:e0135038.

Shiono, M., N. Matsugaki, and K. Takeda. 2005. Structure of the blue cornflower pigment. Nature 436:791.

Shoji, K., N. Miki, N. Nakajima, K. Momonoi, C. Kato, and K. Yoshida. 2007. Perianth bottomspecific blue color development in tulip cv. Murasakizuisho requires ferric ions. Plant Cell Physiol. 48:243-251.

Shoji, K., K. Momonoi, and T. Tsuji. 2010. Alternative expression of vacuolar iron transporter and ferritin genes leads to blue/purple coloration of flowers in tulip cv. 'Murasakizuisho’. Plant Cell Physiol. 51:215-224.

Suzuki, K., T. Suzuki, T. Nakatsuka, H. Dohra, M. Yamagishi, K. Matsuyama, and H. Matsuura. 2016. RNA-seq-based evaluation of bicolor tepal pigmentation in Asiatic hybrid lilies (Lilium spp.). BMC Genomics 17:611.

Takeda, K., A. Osakabe, S. Saito, D. Furuyama, A. Tomita, Y. Kojima, M. Yamadera, and M. Sakuta. 2005. Components of protocyanin, a blue pigment from the blue flowers of Centaurea cyanus. Phyotochemistry 66:1607-1613.

Tanaka, Y. and A. Ohmiya. 2008. Seeing is believing: Engineering anthocyanin and carotenoid biosynthetic pathways. Curr. Opin. Biotechnol. 19:190-197.

Togami, J., H. Okuhara, N. Nakamura, K. Ishiguro, C. Hirose, M. Ochiai, Y. Fukui, M. Yamaguchi, and Y. Tanaka. 2011. Isolation of cDNAs encoding tetrahydroxychacone 2 '-glucosyltransferase activity from carnation, cyclamen, and catharanthus. Plant Biotechnol. 28:231-238.

Veberic, R., A. Slatnar, J. Bizjak, F. Stampar, and M. Mikulic-Petkovsek. 2015. Anthocyanin composition of different wild and cultivated berry species. LWT-Food Sci. Technol. 60:509-517.

Wang, X., C.G. Cheng, Q.L. Sun, F.W. Li, J.H. Liu, and C.C. Zheng. 2005. Isolation and purification of four flavonoid constituents from the flower of Paeonia suffruticosa by high-speed counter-current chromatography. J. Chromatography 1075:127-131.

Wang, L.S., F. Hashimoto, A. Shiraishi, N. Aoki, J.J. Li, and K. Shimizu. 2001a. Phenetics in tree peony species from China by flower pigment cluster analysis. J. Plant Res. 114:213-221.

Wang, L.S., A. Shiraishi, F. Hashimoto, N. Aoki, K. Shimizu, and Y. Sakata. 2001b. Analysis of petal anthocyanins to investigate flower coloration of Zhongyuan (Chinese) and Daikon Island (Japanese) tree peony cultivars. J. Plant Res. 114:33-43.

Yoshida, K., M. Kawachi, M. Mori, M. Maeshima, M. Kondo, M. Nishimura, and T. Kondo. 2005. The involvement of tonoplast proton pumps and $\mathrm{Na}^{+}\left(\mathrm{K}^{+}\right) / \mathrm{H}^{+}$exchangers in the change of petal color during flower opening of morning glory, Ipomoea tricolor cv. Heavenly Blue. Plant Cell Physiol. 46:407-415.

Yoshida, K., S. Kitahara, D. Ito, and T. Kondo. 2006. Ferric ions involved in the flower color development of the Himalayan blue poppy, Meconopsis grandis. Phytochemistry 67:992998.

Yoshida, K., T. Kondo, Y. Okazaki, and K. Katou. 1995. Cause of blue petal colour. Nature 373:291.

Yoshida, K., M. Mori, and T. Kondo. 2009a. Blue flower color development by anthocyanins: From chemical structure to cell physiology. Nat. Prod. Rpt. 26:884-915.

Yoshida, K., N. Miki, K. Momonoi, M. Kawachi, K. Katou, Y. Okazaki, N. Uozumi, M. Maeshima, and T. Kondo. 2009b. Synchrony between flower opening and petal-color change from red to blue in morning glory, Ipomoea tricolor cv. Heavenly Blue. Proc. Jpn. Acad. Ser. B Phys. Biol. Sci. 85:187-197.

Yoshida, K. and T. Negishi. 2013. The identification of a vacuolar iron transporter involved in the blue coloration of cornflower petals. Phytochemistry 94:60-67.

Yoshida, K., Y. Toyama-Kato, K. Kameda, and T. Kondo. 2003. Sepal color variation of Hydrangea macrophylla and vacuolar $\mathrm{pH}$ measured with a proton-selective microelectrode. Plant Cell Physiol. 44:262-268.

Zhang, J.J., L.S. Wang, Q.Y. Shu, Z. Liu, C.H. Li, and J. Zhang. 2007. Comparison of anthocyanins in non-blotches and blotches of the petals of Xibei tree peony. Scientia Hort. 114:104 111.

Zhao, C., W. Guo, and J. Chen. 2005. Formation and regulation of flower color in higher plants. Chinese Bul. Bot. 22:70-81.

Zhao, D., Y. Jiang, C. Ning, J. Meng, S. Lin, W. Ding, and J. Tao. 2014. Transcriptome sequencing of a chimaera reveals coordinated expression of anthocyanin biosynthetic genes mediating yellow formation in herbaceous peony (Paeonia lactiflora Pall.). BMC Genomics 15:689.

Zhao, D. and J. Tao. 2015. Recent advances on the development and regulation of flower color in ornamental plants. Front. Plant Sci. 6:261.

Zhao, D., M. Wei, D. Liu, and J. Tao. 2016. Anatomical and biochemical analysis reveal the role of anthocyanins in flower coloration of herbaceous peony. Plant Physiol. Biochem. 102:97-106.

Zhao, D., M. Wei, M. Shi, Z. Hao, and J. Tao. 2017. Identification and comparative profiling of miRNAs in herbaceous peony (Paeonia lactiflora Pall.) with red/yellow bicoloured flowers. Sci. Rpt. 7:44926.

Zhao, D., W.H. Tang, Z.J. Hao, and J. Tao. 2015. Identification of flavonoids and expression of flavonoid biosynthetic genes in two coloured tree peony flowers. Biochem. Biophys. Res. Commun. 459:450-456.

Zhou, L., Y. Wang, C.Y. Lü, and Z.H. Peng. 2011. Identification of components of flower pigments in petals of Paeonia lutea wild population in Yunnan. J. Northeast For. Univ. 39:52-54. 